\title{
Psychotropic Medication Use Among Children in the Child Welfare System
}

\author{
WENDY A. WALSH AND MARYBETH J. MATTINGLY
}

$\gamma^{\mathrm{p}}$ hildren in the child welfare system are given psychotropic medication at rates approximately three times higher than children and adolescents in the general population. Psychotropic medication refers to drugs prescribed to affect the mind, emotions, and behavior. Previous research finds that 14 percent of children in the child protective system-which includes children who had a report of suspected maltreatment and includes those in foster care, kinship care, and children who remained in their home after the investigation of child abusewere prescribed psychotropic medications from 2001-2002. ${ }^{1}$ In contrast, Medicaid data suggest that 5 percent to 6 percent of low-income children were prescribed psychotropic medication, and prior research suggests rates of 4 percent to 6 percent among children and adolescents in the general population. ${ }^{2} \mathrm{~A}$ recent report by the General Accountability Office (GAO) finds that between 20 percent and 39 percent of foster children in five states (Florida, Massachusetts, Michigan, Oregon, and Texas) were prescribed psychotropic drugs compared with between 5 percent and 10 percent of children receiving Medicaid in those states. ${ }^{3}$ Studies suggest that white race/ethnicity, male gender, older age, history of physical and sexual abuse, foster care (versus in-home), and need for mental health services are all correlated with medication use among child welfare populations. ${ }^{4}$

In some respect, these high rates among children in the child welfare system are not surprising. Nationally, nearly one-half of children in contact with child welfare agencies have clinically significant emotional or behavioral problems. ${ }^{5}$ Furthermore, from the mid-1980s to the mid-1990s, psychotropic medication prescriptions among children in general increased two- to threefold, ${ }^{6}$ with rates continuing to increase in the 2000s. ${ }^{7}$

Variations in rates of prescription by location raise some concerns. One study found that children living in the South were more likely to receive stimulants than those living in other areas of the country. ${ }^{8}$ Another study found that children in mostly rural and mostly urban areas were more likely to receive stimulants than were those living in fully rural areas. The geographic variation remained after controlling for child age and gender. ${ }^{9}$ There was no difference in use between
Key Findings
- Among children age 4 and older with a report of maltreatment, rates of psychotropic medication use are significantly higher in rural (20 percent) than urban areas (13 percent).
- Children age 4 and older with a maltreatment report in rural areas were significantly more likely to take more than one medication than children in urban areas. In rural places, 28 percent took two medications and 33 percent took three or more medications. In urban places, 23 percent took two and 14 percent took three or more medications.
- In addition to emotional or behavioral problems, a number of other factors predicted which children were given psychotropic medication, including whether they receive counseling, being 12 years old or older, and being male.
- In rural places, children living in poor households were more likely to be given psychotropic medication.
- Twenty percent of children in rural areas with a child maltreatment report who remain in-home received medication compared to 12 percent in urban areas.

children living in fully rural and fully urban areas, and physician supply rate (that is, the number of physicians by area) was not significantly associated with use. Two other small studies found no differences in stimulant use in rural or urban areas. ${ }^{10}$

Likewise, results from studies focusing only on children in the child welfare system vary by location. For example, one study found that only 7 percent of California children in the child welfare system were taking psychotropic medications while 20 percent of such children in Texas were. ${ }^{11}$ Another study found 
rates varied between 0 percent and 40 percent across a variety of locations. ${ }^{12}$ Both studies found few contextual factors (such as Medicaid generosity, per capita rate of psychiatrists, or county poverty rates, among others) predicted medication use. Instead, child characteristics were more important predictors.

Thus, place appears to be important in determining whether children involved with the child welfare system receive psychotropic medication. Therefore, understanding psychotropic medication use in rural versus urban areas can help determine if some children disproportionally receive medical, rather than other, interventions in rural or urban areas and provide a better understanding of need, which can contribute to meaningful policy and resource allocation discussions.

\section{Psychotropic Medication Use}

Using data from the second National Survey of Child and Adolescent Well-Being (NSCAW II), we find that among children age 4 and older with a maltreatment report, rates of psychotropic medication use are significantly higher in rural than urban areas (see Figure 1). ${ }^{13}$ Twenty percent of children with a maltreatment report in rural areas currently receive medication compared with 13 percent of those in urban areas. More rural children have also ever been given psychotropic medication: 27 percent of children with a maltreatment report in rural areas had ever received medication compared with 19 percent of those in urban areas.

Children with a maltreatment report receiving medication

Figure 1. Psychotropic medication use by Place, AMONG CHILDREN 4 AND OLDER WITH A CHILD MALTREATMENT REPORT

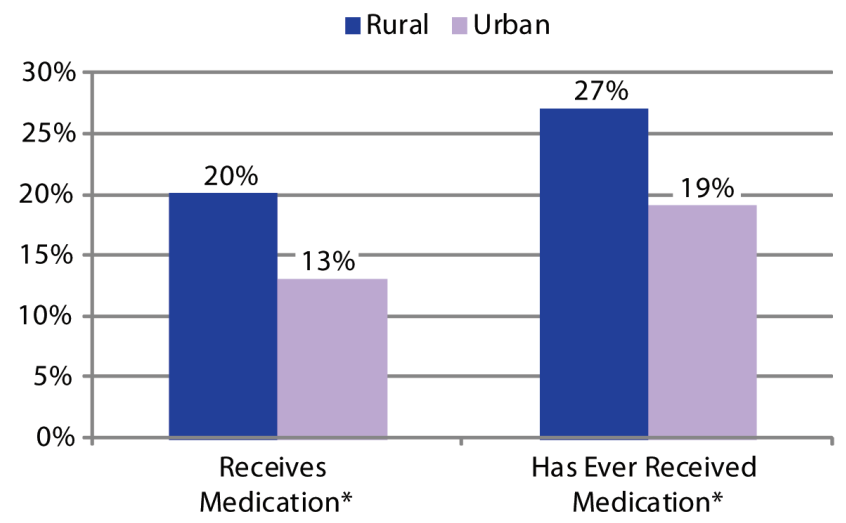

Note: An asterisk $\left(^{*}\right)$ indicates statistically significant differences $(p<0.05)$. Source: NSCAW II

in rural areas were significantly more likely to take multiple medications than were those in urban areas (see Figure 2). Specifically, in rural places, 33 percent of children were given three or more medications compared with 14 percent of children in urban places.
Figure 2. Number of Psychotropic Medications By Place

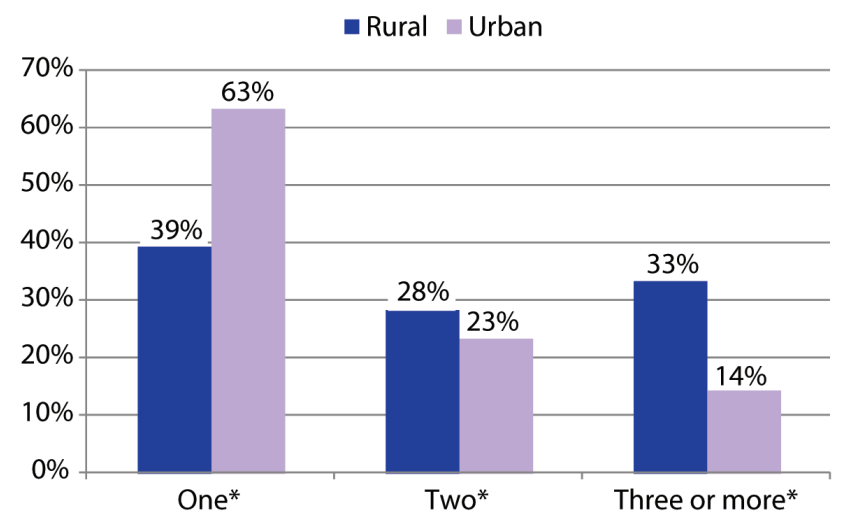

Note: An asterisk $\left.{ }^{*}\right)$ indicates statistically significant differences $(p<0.05)$. Source: NSCAW II

\section{Need for Psychotropic Medication}

Nationally, an estimated 42 percent of children with a maltreatment report who also have emotional/behavioral problems take psychotropic medication, with no differences in use of medication in rural or urban areas. Children with a maltreatment report in rural areas were significantly more likely to have a diagnosis of $\mathrm{ADD} / \mathrm{ADHD}$ at the time of the maltreatment investigation (28 percent) than were children in urban areas (20 percent) (see Figure 3). However, there was no difference in use when examining only the group of children with ADD/ADHD. There were no other significant diagnostic differences by place. Overall, the most common diagnosis was ADD/ADHD (22 percent), followed by an emotional problem (19 percent), developmental delay (5 percent), and autism (3 percent).

FiguRE 3. EMOTIONAL OR BEHAVIORAL PROBLEMS AMONG CHILDREN 4 AND OLDER WITH A CHILD MALTREATMENT REPORT

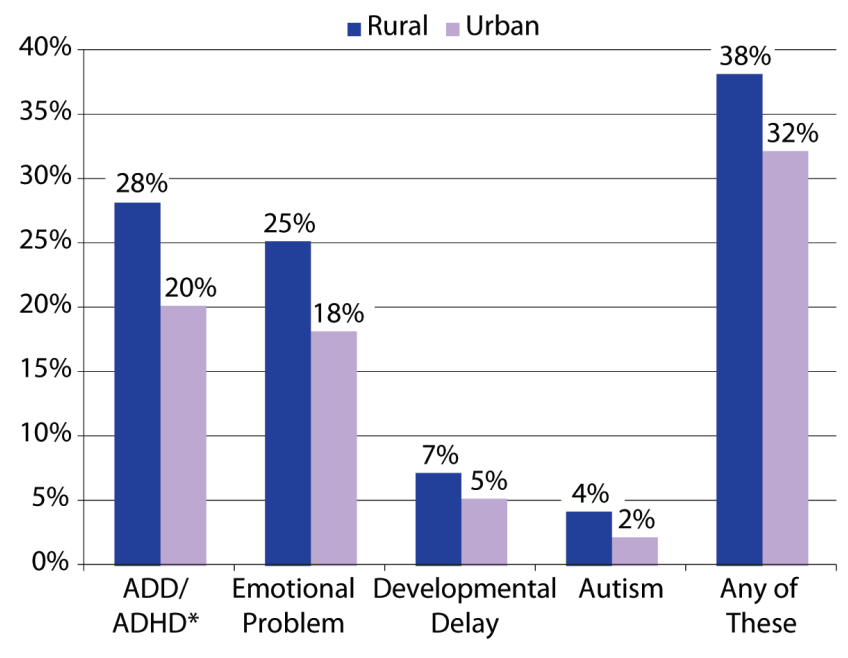

Note: An asterisk $\left(^{*}\right)$ indicates statistically significant differences $(p<0.05)$. Source: NSCAW II 


\section{Characteristics of Children Receiving Medication}

There were several significant differences in the characteristics of children receiving medication in rural and urban places (see Table 1). In rural places, children with a maltreatment report receiving medication were significantly more likely than those in urban places to be:

- Older: 36 percent of children aged 12-17 in rural places with a maltreatment report receive medication versus 12 percent in urban places.

- Girls: 19 percent of girls in rural places with a maltreatment report receive medication versus 8 percent in urban places.

- Living at home after the child abuse investigation (that is, not removed because of concerns for safety): 20 percent of children with a maltreatment report who are living at home in rural places receive medication versus 12 percent in urban places.

- Poor: 29 percent of rural children with a maltreatment report and living in poor households-whose income is 50 percent to 100 percent of the federal poverty levelreceive medication versus 12 percent in urban places.

There was no difference across rural and urban areas in receiving medication by race/ethnicity or whether the child received counseling. About 21 percent of white children received medication in both rural and urban areas, and 10 percent of minority children received medication in both rural and urban areas. Nearly one-half of children receiving counseling in both rural and urban areas were also taking psychotropic medications.

To understand the impact of these characteristics in rural versus urban places, we conducted a multivariate logistic regression model. This analysis simultaneously accounts for many possible factors and determines the probability of psychotropic medication use for each individual factor net of the others. This type of analysis is important because it accounts for factors that tend to cooccur. Children with an emotional or behavioral problem had the highest probability of psychotropic medication use. ${ }^{14}$ Children who receive counseling, children who are 12 years old or older, and boys had higher probabilities of psychotropic medication use, net of other factors.

Because characteristics of children on medication in rural and urban areas differed, we also included four interaction terms in the regression (rural and poor, rural and child aged 12 or older, rural and boy, and rural and out-of-home placement). This is important because it allows us to examine the association of psychotropic medication use for these particular characteristics, controlling for other factors. Even accounting for other
TABle 1. CharaCteristics OF CHILDREN 4 AND OLDER WITH A CHILD MALTREATMENT REPORT RECEIVING MEDICATION BY PLACE

\begin{tabular}{l|c|c}
\hline \multicolumn{1}{c|}{ Characteristic } & \% Rural Children & \% Urban Children \\
\hline Child's age & 11 & 14 \\
$\quad 4$ to 11 & 36 & 12 \\
12 to $17^{*}$ & 21 & 19 \\
Child's gender & 19 & 8 \\
$\quad$ Male & & \\
$\quad$ Female* & 20 & 12 \\
Child's placement & 18 & 22 \\
In-home* & & \\
Out of home & 17 & 12 \\
Federal poverty level & 29 & 12 \\
$<50 \%$ & 17 & 12 \\
$50-<100 \% *$ & 14 & 17 \\
100-200\% & & 20 \\
$\quad<200 \%$ & 21 & 10 \\
Child's race/ethnicity & 16 & \\
White, non-Hispanic & & 44 \\
Minority & 50 & 7 \\
Child receives counseling & 9 & \\
Yes & & \\
No &
\end{tabular}

Note: An asterisk $\left({ }^{*}\right)$ indicates statistically significant differences $(p<0.05)$. Source: NSCAW II

characteristics, rural children living in poor households (less than 100 percent of federal poverty), and those aged 12 and older had higher probabilities of receiving psychotropic medication than their urban peers.

\section{Understanding Psychotropic Medica- tion Use in Rural and Urban Places}

The significantly higher rates of psychotropic medication use among children in rural areas and the significantly higher rates of taking multiple medications point to the need among child welfare professionals in rural areas to closely monitor use. There were several significant differences in the characteristics of children receiving medication in rural and urban places. In rural places, children receiving medication were more likely to be older, girls, living at home, and poor compared to those receiving medication in urban places. When used appropriately medications can provide a viable treatment option. However, it is generally recommended that prescriptions be closely monitored, especially when children are prescribed more than one medication. ${ }^{15}$

A number of factors may play a role in the patterns of psychotropic medication use in the child welfare system, including: ${ }^{16}$ 
- Insufficient state oversight and monitoring of psychotropic medication use

- Gaps in coordination and continuity of medical and mental health care across public health and social service systems

- Provider shortages, especially of board-eligible and board-certified child and adolescent psychiatrists, especially in rural areas

- Lack of access to effective nonpharmacological treatments in outpatient settings

The Administration on Children, Youth, and Families (ACF) has focused on the social and emotional well-being among children involved in foster care. ${ }^{17}$ For example, a new requirement mandated in the Child and Family Service Improvement and Innovation Act (P.L. 112-34) requires states to include a psychotropic medication oversight plan in their "State Child and Family Service Plans" when children enter out-of-home care. ${ }^{18}$ Given the high rates of use, this is encouraging oversight. However, this requirement does not address psychotropic medication use among children who remain in their home. Given that 20 percent of children in rural areas with a child maltreatment report who remain in-home are receiving medication, it would be beneficial for child welfare professionals and pediatricians to help educate parents about access to both pharmacological and nonpharmacological behavioral treatments. Doing so can help ensure that children in need are receiving appropriate services. Because rates of counseling did not differ across place type, it will still be important to maintain or enhance access to nonpharmacological treatment across rural and urban America. Although we did not explore the topic here, future research should consider how the quality of services might differ across place.

Much more information is needed to better understand the use and impact of such medication. For example, few studies have examined the safe and appropriate pediatric use of psychotropic medication, ${ }^{19}$ and there is even less evidence of the effectiveness of pharamacologic interventions for treating trauma-related symptoms in children. ${ }^{20}$ In the absence of such research, it is not possible to adequately assess the positive and negative short- and long-term effects of psychotropic medication use. ${ }^{21}$

Medication can be an important component of a comprehensive response to the mental health needs of children. However, as described in the recent memorandum by the ACF, current use of psychotropic medications among children in foster care and among the child welfare population may exceed practice standards. ${ }^{22}$ The memorandum emphasizes that greater oversight of psychotropic medication is necessary, with enhanced collaboration among child welfare agencies, families, and professionals and organizations providing mental health services. The results of the current analysis indicate that more information is needed about the complex decision-making process regarding medication use. This includes a need to better understand how who ultimately decides may make a difference in use, how pediatric clinicians make decisions, and the impact of community norms on medication use. ${ }^{23}$ The results presented here provide a first step in increasing awareness about characteristics of children receiving medication. This information may help professionals working with children involved with the child welfare system and ensure that effective treatment plans are in place for children.

\section{Data}

All fifty states, the District of Columbia, and U.S. Territories have mandatory child abuse and neglect reporting laws that require certain professionals and institutions to report suspected maltreatment to a child protection services (CPS) agency. CPS then investigates the reports of suspected maltreatment. The data for this analysis come from a national sample of children who had a maltreatment report that resulted in an investigation: the second National Survey of Child and Adolescent Well-Being (NSCAW II). It includes both substantiated cases, cases with sufficient evidence to determine that child maltreatment has occurred, and unsubstantiated cases, cases in which maltreatment cannot be substantiated. The NSCAW II study design mirrors that of NSCAW I, which collected data on children involved with CPS beginning in 1999. The NSCAW II cohort includes 5,873 children, aged birth to 17.5 years old, who had contact with the child welfare system within a fifteenmonth period beginning in February 2008. A two-staged cluster sampling strategy was used. Information on the NSCAW II study design and sampling procedure has been previously published. ${ }^{24}$ Face-to-face interviews were conducted with children, parents, and nonparent adult caregivers and investigative caseworkers. Statistics were computed using survey weights to account for the complex sampling design of NSCAW. All differences discussed are statistically significant at the 95 percent confidence level $(\mathrm{p}<.05)$.

The sample for this analysis included 2,561 children aged 4 to 17.5 years old because initial analysis indicated psychotropic medication typically began at age 4 (only three children younger than age 4 were on medication). Most of the children in the sample (87 percent) were living at home; 13 percent were living out-of-home.

The urbanicity of the primary sampling unit (PSU)/ county was calculated using the Census Bureau definitions for the entire county/PSU. Urban was defined as greater than 50 percent of the population living in an urban area, whereas nonurban/rural was defined as all areas that did not meet this requirement.

A few caveats should be mentioned. NSCAW's data confidentiality agreements preclude analysis by county. Therefore, our analysis focused on the urbanicity of the area served by the child welfare agency. However, it could be that the impact of urbanicity may vary by the state. We did not have information 


\section{Definitions}

Current use of psychotropic medication is indicated when a caregiver answered yes to "Is child currently taking any medication for emotional or behavioral problems?" Ever using psychotropic medication is indicated when a caregiver answered yes to "To your knowledge, has child ever taken any medication prescribed by a doctor or clinician for emotional or behavioral problems?"

Emotional or behavior problems are indicated when a caregiver answered yes to whether their child has attention deficit disorder or attention deficit hyperactivity disorder (ADD or ADHD); autism, autism spectrum disorder (ASD); mental retardation or developmental delay; or depression, anxiety, an eating disorder, or other emotional problems.

Any counseling services are indicated when a caregiver answered yes to their child receiving counseling services at a mental health community center, private practice, or in-home counseling services in the past twelve months.

about the experience or training of the prescriber, which could likely affect rates. We also lacked information on whether use is indicative of appropriate or inappropriate use. Future research should consider some of these additional considerations of use.

\section{E N D N O T E S}

1. Ramesh Raghavan et al.,"Psychotropic Medication Use in a National Probability Sample of Children in the Child Welfare System," Journal of Child and Adolescent Psychopharmacology, vol. 15, no. 1 (2005): 97-106.

2. A. Martin et al., "Multiple Psychotropic Pharmacotherapy among Child and Adolescent Enrollees in Connecticut Medicaid Managed Care," Psychiatric Services, vol. 54 (2003): 72-77; M. Olfson et al., "National Trends in the Use of Psychotropic Medications by Children," Journal of the American Academy of Child and Adolescent Psychiatry, vol. 41 (2002): 514-521; J. Zito et al., "Psychotropic Practice Patterns for Youth: A 10-Year Perspective," Archives of Pediatric Adolescent Medicine, vol. 157 (2003): 17-25; G. A. Simpson et al., "Use of Mental Health Services in the Past 12 Months by Children aged 4-17 Years: United States 2005-2006," NCHS data brief (Washington, DC: 2008), www.cdc.gov/nchs/data/ databriefs/db08.pdf (retrieved September 11, 2012).

3. General Accountability Office, "HHS Guidance Could Help States Improve Oversight of Psychotropic Prescriptions" (Washington, DC: GAO, December 2011).

\section{A. Breland-Noble et al., "Use of Psychotropic}

Medications by Youths in Therapeutic Foster Care and Group Homes," Psychiatric Services, vol. 55 (2004), 706-
708; R. Raghavan and J. McMillen, "Use of Multiple Psychotropic Medications among Adolescents Aging Out of Foster Care," Psychiatric Services, vol. 59 (2008): 1052-1055; Raghavan, "Psychotropic Medication Use in a National Probability Sample"; L.F. Stambaugh et al., Psychotropic Medication Use by Children in Child Welfare (Washington, DC: Office of Planning, Research and Evaluation, Administration for Children and Families, U.S. Department of Health and Human Services, 2012).

5. B. J. Burns et al., "Mental Health Need and Access to Mental Health Services by Youths Involved with Child Welfare: A National Survey," Journal of American Academy of Child and Adolescent Psychiatry, vol. 43, no. 8 (2004): 960-970.

6. R. Goodwin et al., "Prescription of Psychotropic Medications to Youths in Office-Based Practice," Psychiatric Services, vol. 52 (2001): 1081-1087; Martin et al., "Use of Multiple Psychotropic Drugs"; Olfson et al., "National Trends in the Use of Psychotropic Medications"; Zito et al., "Psychotropic Practice Patterns."

7. R. Mojtabai and M. Olfson, "National Trends in Psychotropic Medication Polypharmacy in Office-Based Psychiatry," Archives of General Psychiatry, vol. 67 (2010): 26-36; M. Olfson et al., "National Trends in the Outpatient Treatment of Children and Adolescents with Antipsychotic Drugs," Archives of General Psychiatry, vol. 63 (2006): 689-685.

8. K. Hoagwood et al., "Medication Management of Stimulants in Pediatric Practice Settings: A National Perspective," Journal of Developmental and Behavioral Pediatrics, vol. 21 (2000): 322-331.

9. E. Cox et al., "Geographic Variation in the Prevalence of Stimulant Medication Use Among Children 5 to 14 Years Old: Results from a Commercially Insured U.S. Sample," Pediatrics, vol. 111, no. 2 (2003): 237-243.

10. M. Rappley et al., The Use of Methylphenidate in Michigan," Archives of Pediatric Adolescent Medicine, vol. 149, (1995): 675-679; R. Bussing et al., "Children in Special Education Programs: Attention Deficit Hyperactivity Disorder, Use of Services, and Unmet Needs," American Journal of Public Health, vol. 88 (1998): 880-886.

11. R. Raghavan et al. "Interstate Variation in Psychotropic Medication Use Among a National Sample of Children in the Child Welfare System," Child Maltreatment, vol. 15, no 2 (1998): 121-131.

12. L. Leslie et al., "Investigating Geographic Variation in Use of Psychotropic Medications Among Youth in Child Welfare," Child Abuse and Neglect, vol. 35 (1998): 333-342.

13. Only children age 4 and older were included in the analysis described here because medication use increased at age 4 (only three children younger than age 4 were on medication). In the text when we refer to children in the analysis, we are referring to children age 4 and older. 
14. Analysis controls for out-of-home placement, race/ ethnicity, rural or urban area, poverty level, and two interactions terms rural and boy and rural and out-of-home placement.

15. U.S. Department of Health and Human Services, Information Memorandum: Promoting the Safe, Appropriate, and Effective Use of Psychotropic Medication for Children in Foster Care (Washington, DC: Administration on Children Youth and Families, Administration for Children and Families, 2012); Mojtabai and Olfson, "National Trends in Psychotropic Medication Polypharmacy."

16. T. Mackie et al., "Psychotropic Medication Oversight for Youth in Foster Care: A National Perspective on State Child Welfare Policy and Practice Guidelines," Child and Youth Services Review, vol. 33 (2011): 2213-2220.

17. DHHS, Information Memorandum.

18. Ibid.

19. P. Jensen, "Psychoactive Medication Prescribing Practices for U.S. Children: Gaps between Research and Clinical Practice," Journal of the American Academy of Child and Adolescent Psychiatry, vol. 38, no. 5 (1999): 557-565.

20. H. Wethington, et al., "The Effectiveness of Interventions to Reduce Psychological Harm from Traumatic Events among Children and Adolescents: A Systematic Review," American Journal of Preventative Medicine, vol. 35, no. 3 (2008): 287-313.

\section{DHHS, Information Memorandum.}

22. Ibid; Stambaugh, Psychotropic Medication Use.

23. Leslie, "Investigating Geographic Variation"; M. Naylor et al., "Psychotropic Medication Management for Youth in State Care," Psychiatric Services, vol. 55, no. 7 (2007): 811-817.

24. M. Dolan et al., NSCAW II Baseline Report: Introduction to NSCAW II Final Report, OPRE Report \#2011-27a (Washington, DC: Office of Planning, Research and Evaluation, Administration for Children and Families, U.S. Department of Health and Human Services, 2011), www.acf.hhs.gov/programs/opre/index.html.

\section{ABOUT THE AUTHORS}

Wendy A. Walsh is a research associate professor of sociology at the Crimes against Children Research Center and a research associate at the Carsey Institute at the University of New Hampshire (wendy.walsh@unh.edu).

Marybeth J. Mattingly is director of research on vulnerable families at the Carsey Institute and a research assistant professor of sociology at the University of New Hampshire (beth.mattingly@unh.edu).

\section{A C K N O W L E D G E M E N T S}

We are grateful for the substantive and editorial comments and suggestions from David Finkelhor at the University of New Hampshire's Crimes against Children Research Center, Barbara Ray at Hired Pen, and Bruce Mallory, Curt Grimm, Amy Sterndale, and Laurel Lloyd at the Carsey Institute.

This document includes data from the National Survey on Child and Adolescent Well-Being, which was developed under contract with the Administration on Children, Youth, and Families, U.S. Department of Health and Human Services (ACYF/DHHS). The data have been provided by the National Data Archive on Child Abuse and Neglect. The information and opinions expressed herein reflect solely the position of the authors. Nothing herein should be construed to indicate the support or endorsement of its content by ACYF/DHHS.

\section{ANIVERSITY}

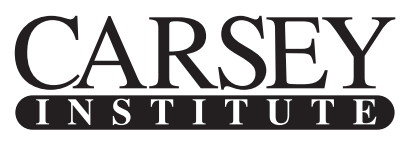

Building knowledge for families and communities

The Carsey Institute conducts policy research on vulnerable children, youth, and families and on sustainable community development. We give policy makers and practitioners timely, independent resources to effect change in their communities.

This work was supported by the Annie E. Casey Foundation, the W. K. Kellogg Foundation, and anonymous donors.

Huddleston Hall

73 Main Street

Durham, NH 03824

$(603) 862-2821$

www.carseyinstitute.unh.edu 